\title{
OS COTIDIANOS - espaçostempos de resistência e criação
}

\author{
Nilda Guimarães Alves \\ Universidade do Estado do Rio de Janeiro - UERJ \\ Carlos Eduardo Ferraço \\ Universidade Federal do Espírito Santo - UFES \\ Marco Antonio Oliva Gomes \\ Universidade Federal do Espírito Santo - UFES
}

\begin{abstract}
Resumo
Trata-se de texto que tem como principal objetivo afirmar a potência dos cotidianos como espaçostempos de resistência e de criação frente às agendas de liquidação do social presentes no Brasil e no mundo, aliadas que estão às políticas de transcendência opressora e de diminuição da vida, que incluem os mecanismos de normalização, controle, servidão e de tentativa de anulação da diferença que se alojam nos organismosinstituições e que se fazem cada vez mais avassaladoras nas escolas, não se tornando totalitárias exatamente por conta das práticas cotidianas que reinventam a vida. Parte de problematizações iniciais dando especial atenção aos acontecimentos que insurgem em meio às tessituras dos conhecimentossignificações, cujas temporalidades nos forçam a pensar na potência da multiplicidade e da diferença presentes nos processos cotidianos de criação e de resistência, que emergem em meio aos currículos tecidos em redes e que necessitam ser assumidos fora das lógicas identitárias, de recognição e de representatividade. Aposta na ideia de corpos sem órgãos associada à reorganização das forças intensivas, à revolução por novas formas de existência, à proposição de uma dimensão ético-estético-política para a vida, à luta pela libertação das malhas dos poderes opressores ou, ainda, à produção da máquina de guerra nômade. Por fim, considera que a guerra a ser travada nos dias atuais vai além daquela contra os organismos, precisando se constituir como uma guerra pela vida, pela libertação das forças vitais aprisionadas no homem e pelo próprio homem. Uma guerra que possa romper com a opressão das forças vitais que torna o corpo refém dos poderes que estão a serviço morte.
\end{abstract}

Palavras-chave: Cotidiano. Resistência. Criação. Corpo sem órgãos. Máquina de guerra.

\begin{abstract}
It is a text whose main objective is to affirm the power of everyday life as spacetime of resistance and creation in face of the social-liquidation agendas present in Brazil and in the world, allied to the policies of oppressive transcendence and diminishing life, which include the mechanisms of normalization, control, servitude, and attempts to nullify the difference that are lodged in the institutions-organisms and that are becoming increasingly overwhelming in schools, not becoming totalitarian precisely because of everyday practices that reinvent life. It departs from initial problematization, paying special attention to the events that arise among the weavings of knowledge-meanings, whose temporalities force us to think about the power of multiplicity and difference present in the daily processes of creation and resistance, which emerge amid the curricula woven into networks and that need to be assumed outside the logic of identity, recognition and representativeness. It bets on the idea of bodies without organs associated to the reorganization of intensive forces, to the revolution for new forms of existence, to the proposition of an ethical-aesthetic-political dimension for life, to the struggle for the liberation from the meshes of oppressive powers or even to the nomad war machine of production. Finally, it considers that the war to be waged today goes beyond that against organisms, and must be constituted as a war for life, for the liberation of vital forces imprisoned in man and by man himself. A war that can break with the oppression of vital forces that makes the body hostage to the powers that serve death.
\end{abstract}

Keywords: Everyday life. Resistance. Creation. Body without organs. War machine.

ISSN 1645-1384 (online) www.curriculosemfronteiras.org 


\section{Introdução: cotidianos, currículos, processos de resistência e de criação}

Decorridos quase quinze anos da publicação do texto "Uma história da contribuição dos estudos do cotidiano escolar ao campo do currículo” (ALVES; OLIVEIRA, 2002), faz-se necessário afirmar, quantas vezes forem necessárias e, sobretudo nos dias atuais, a importância de se praticarpensar os cotidianos, sempre no plural, como espaçostempos (ALVES, 2004) de resistência e de criação, protagonizados que são pelos praticantespensantes (OLIVEIRA, 2012), em meio às múltiplas e complexas redes tecidas, que se expandem e não se deixam capturar.

No referido texto, as autoras (2002) alertavam para a necessidade de se superar os tradicionais enfoques herdados do discurso hegemônico do paradigma moderno que, ao priorizar a lógica da quantificação, associavam o cotidiano, sempre no singular, à norma, à repetição, à obviedade, à regulação, à alienação e, dessa forma, desprovido de qualquer possibilidade de criação e/ou de resistência. Para as autoras (2002, p. 83-86):

A partir desses estudos iniciais e discutindo com eles, muitas vezes os estudos desenvolvidos atualmente, no que se refere aos tantos cotidianos nos quais nos formamos como uma 'rede de subjetividades' (SANTOS, 1995), dentre as quais está o da escola, fundamentam-se em uma crítica ao modelo da ciência moderna que, para se 'construir', teve a necessidade de considerar os conhecimentos cotidianos como 'senso comum' a ser superado, de modo indispensável, pelo conhecimento científico [....].

Se, entretanto, recuperamos da nossa vida os aspectos singulares e qualitativos dessas práticas, aparentemente repetidas ad infinitum, vamos nos dar conta de que, na forma e fazer de cada uma dessas atividades, nunca há repetição.

Mesmo considerando as agendas de liquidação do social presentes no Brasil e no mundo pautadas, entre outras coisas, pelas tentativas de normalização, de controle e de destruição da vida, é vital que possamos assumir os cotidianos, em especial os das escolas, como espaçostempos de acasos, de multiplicidades e de diferenças afirmando, dessa forma, sua dimensão ético-estético-política, à medida vamos tecendo novas formas de entendimento tanto das teorias com as quais trabalhamos quanto dos processos de criação e de resistência que acontecem com os conhecimentossignificações aqui assumidos como possibilidade de não se sucumbir à morte, como alternativa de produção de outros modos de existência. Como alertam as autoras (2002, p. 89):

Portanto, para compreender as lógicas que presidem a vida cotidiana, precisamos nela 'mergulhar'; (OLIVEIRA ALVES, 2001), aceitando a impossibilidade de obtermos 'dados relevantes gerais' em meio à realidade caótica e à necessidade de considerar a relevância de todos os seus elementos constitutivos, em suas infinitas relações e consequências. 
Nesse sentido, o primeiro movimento necessário para se conhecer os nossos cotidianos é o de compreender que precisamos aceitar que as tantas teorias aprendidas, sobretudo como limite e não só como potencialidade em nossas pesquisas, na medida em que elas foram 'construídas' negando a existência desses cotidianos e dos conhecimentos que neles são tecidos.

Considerando, então, as teorias aprendidas sempre como limites e não mais como solucionadoras de nossas questões de pesquisa, vamos dar especial atenção àquilo que insurge em meio às tessituras das redes cotidianas de conhecimentossignificações, isto é, por entre os acontecimentos (DELEUZE, 2007) que não se deixam representar e que, por sua dimensão ético-estético-política, potencializariam novos modos de subjetivação emergentes, movimentos coletivos de enunciação, outros territórios existenciais, que nos possibilitariam produzir formas de combater os modelos opressores do capital e todo e qualquer conservadorismo que, nos dias atuais, se mostram, sobretudo, na defesa de valores morais, sexistas, racistas, homofóbicos, xenófobos, entre outros que têm na diminuição da vida sua aposta maior.

Em termos das problematizações mais amplas que temos realizado no campo do currículo pensamos que, para além da presença impositiva e excludente dos inúmeros discursos curriculares homogeneizantes oficiais que, sistematicamente, buscam limitar o campo de sentidos em termos do que pode ou não ser considerado currículo contribuindo, desse modo, para a negação das dimensões de multiplicidade, diferença e permanente abertura que marcam esse campo, temos nos empenhado em produzir deslizamentos de sentidos em relação ao currículo, de modo a rasurar toda e qualquer definição e/ou representação que se pretenda fixa/definitiva.

Assim, pensando currículo na sua condição de composições e aberturas, temos usado expressões como: currículo-em-redes, currículo-menor, currículo-devir, currículo-fluxo, currículo-nômade, currículo-híbrido, currículo-rizoma, currículo-acontecimento, entre outras, movidos pela impossibilidade de defesa de se fechar um sentido único para o campo e, ainda, pela pista dada por Deleuze e Guattari (2001) quando inferem que conceitos são meteoritos, não mercadorias. Para os autores (2001, p. 20):

Os filósofos não se ocuparam o bastante com a natureza do conceito como realidade filosófica. Eles preferiram considerá-lo como um conhecimento ou uma representação dados que se explicam por faculdades capazes de formá-lo (abstração ou generalização) ou de utilizá-lo (juízo). Mas o conceito não é dado, é criado, está por criar; não é formado, ele próprio se põe em si mesmo. Autoposição. As duas coisas se implicam, já que o que é verdadeiramente criado, do ser visto à obra de arte, desfruta por isso mesmo de uma autoposição de si, ou de um caráter autopoiético pelo qual ele é reconhecido. Tanto mais o conceito é criado, mais ele se põe.

Estamos interessados em produzir um campo discursivo para o currículo sem demarcações conceituais fixas, sempre provisório, cuja potência estaria nos intermezzos que 
insurgem nos cotidianos das escolas. Por serem da ordem do caos e do acaso, aqui não seriam possíveis idealizações, generalizações, transcendências ou recognições, uma vez que, como inferem Deleuze e Guattari (2001, p. 181) “de todos os movimentos, mesmo finitos, do pensamento, a forma da recognição é certamente a que vai menos longe, a mais pobre e infantil”. Quanto à transcendência, os referidos autores (2001, p. 98) defendem que:

Não temos a menor razão para pensar que os modos de existência tenham necessidade valores transcendentes que os comparariam, os selecionariam e decidiriam que um é 'melhor' que o outro. Ao contrário, não há critérios senão imanentes e uma possibilidade de vida se avalia nela mesma, pelos movimentos que ela traça e pelas intensidades que ela cria sobre um plano de imanência; é rejeitado o que não traça nem cria.

Nesse sentido, no lugar da recognição arbórea e das ilusões de transcendências tão em voga nos atuais discursos curriculares governamentais, como a Base Nacional Comum Curricular (BNCC) defendemos, como já antecipado, diferentes possibilidades de praticarpensar currículos, cuja força maior estaria na sua condição de redes, de rizomas pois, como atestam Deleuze e Guattari (1996, p. 37):

Um rizoma não começa nem conclui, ele se encontra sempre no meio, entre as coisas, inter-se, intermezzo. A árvore impõe o verbo 'ser', mas o rizoma tem como tecido a conjunção ‘e... e... e...'. Há nesta conjunção força suficiente para sacudir e desenraizar o verbo ser [...]. É que o meio não é uma média; ao contrário, é o lugar onde as coisas adquirem velocidade. 'Entre' as coisas não designam uma correlação localizável que vai de uma para outra e reciprocamente, mas uma direção perpendicular, um movimento transversal que as carrega uma 'e' outra, riacho sem início nem fim, que rói suas duas margens e adquire velocidade no meio.

\section{Acontecimento, multiplicidade e diferença}

Em “A lógica do sentido”, Deleuze (2007) aborda o acontecimento a partir de três movimentos: seu conceito, seu aspecto temporal e suas singularidades. Em termos gerais, podemos pensar que, para o autor (2007), o acontecimento se dá como um efeito de superfície, algo que insurge, mas que não se reduz às coisas em si, isto é, não se deixa representar, nem identificar, só podendo ser pensado no instante em que acontece. Não seriam corpos, mas, incorporais. Não seriam qualidades, nem propriedades físicas, mas, acontecimentos. Como escreve Deleuze (2007, p. 5):

O único tempo dos corpos e estados de coisas é o presente [...] só os corpos existem no espaço e só o presente no tempo.

Não há causas e efeitos entre os corpos: todos os corpos são causas, causas uns com relação aos outros, uns para com os outros [...]. 
Todos os corpos são causas uns para com os outros, uns com relação aos outros, mas de que? São causas de certas coisas da natureza completamente diferentes. Estes efeitos não são corpos, mas, propriamente falando, 'incorporais’ [...]. Não são coisas ou estados de coisas, mas acontecimentos. Não se pode dizer que existam, mas, antes, que subsistem ou insistem [...]. Não são substantivos ou adjetivos, mas verbos.

Pensar, então, com os acontecimentos cotidianos implica tentar escapar de toda e qualquer possibilidade de representação, definição identitária, decifração, descrição ou explicação do que aconteceu, uma vez que o “acontecido” sempre estará agenciado pelo momento presente em que se dá. Será sempre alguma coisa da ordem do intempestivo, do atual, que só poderá ser problematizada no instante em que insurge. Ao pensar sobre a temporalidade dos acontecimentos, Deleuze (2007, p. 6) infere:

Não são presentes vivos, mas infinitivos: ‘Aion’ ilimitado, devir que se divide ao infinito em passado e em futuro, sempre se esquivando do presente. De tal forma que o tempo deve ser apreendido duas vezes, de duas maneiras complementares, exclusivas uma da outra: inteiro como presente vivo nos corpos que agem e padecem, mas inteiro vivo também, como instância infinitivamente divisível em passado-futuro, nos efeitos incorporais que resultam dos corpos, de suas ações e de suas paixões. Só o presente existe no tempo e reúne, absorve o passado e o futuro, mas só o passado e o futuro insistem no tempo e dividem ao infinito cada presente. Não três dimensões sucessivas, mas duas leituras simultâneas do tempo.

As temporalidades postas por Deleuze (2007) para o acontecimento, nos forçam a pensar na potência da multiplicidade e da diferença presente nos processos cotidianos de criação e de resistência que emergem em meio aos currículos tecidos em redes e só podem ser compreendidos fora das lógicas da recognição, da representatividade, da identidade, da moral transcendente castradora e do tempo chronos. Atentos às referidas agendas de liquidação do social presentes no Brasil, vamos nos dar conta que é exatamente essa a sua maior intenção: nos destituir e impor uma tirania sobre nossa vida, oprimir nossas formas vitais, tornando nossos corpos reféns dos poderes que estão a serviço da morte, paralisar-nos.

As temporalidades, as multiplicidades e os processos de diferenciação inerentes aos acontecimentos, nos convocam a pensar nas dimensões de atualidade e de virtualidade que marcam os próprios acontecimentos. Ao afirmarem que toda multiplicidade implica elementos reais-atuais, jogando por terra a possibilidade de existir um objeto puramente realatual, Deleuze, em Deleuze e Parnet (2004, p. 179-180) conclui:

Qualquer real se rodeia de uma bruma de imagens virtuais. Esta bruma eleva-se de circuitos coexistentes mais ou menos extensos, nos quais as imagens virtuais se distribuem e deslizam [...]. Qualquer real se rodeia de círculos de virtualidades sempre renovados, em que cada um emite um outro, e todos rodeiam o real e reagem nele [...]. Uma percepção é como uma partícula: uma percepção real rodeia-se de uma névoa de imagens virtuais que se distribuem por circuitos 
móveis cada vez mais afastados, cada vez mais amplos que se fazem e se desfazem.

Com isso, é possível entender o acontecimento de modo afirmativo, isto é, a partir de seus processos de singularização, de seus fluxos, de suas multiplicidades e diferenças na imanência da vida, nos espaçostempos da vida cotidiana. Barros, Munari e Abramowicz (2017, p. 112-113), nos ajudam nessa discussão ao afirmarem que:

O atual é o modo como uma pessoa-identidade se apresenta em nosso mundo. Mas reduzir esse modo de apresentação à identidade é reduzir a zero todos os outros modos de existência possíveis que coabitam neste mundo. Essa 'nuvem' de possibilidades, chamada virtual, tanto antecede o atual, como também é quem se atualiza. Isto é, quando falamos em diferença, estamos falando de um virtual que se atualizou [...]. Podemos perceber que na atualização de um virtual não há nenhuma determinação, sendo que o mesmo sequer está direcionado a um ser, muito menos a um indivíduo [....]. O que temos no atual são as repetições. As repetições, sempre diferidas, são também imanentes e tornam possível uma nova atualização do virtual. Vale ressaltar que não é uma operação transcendental, mas sim imanente. Não devemos cair no erro de pensar que existe aí um pensamento binário, uma vez que o atual é uma virtualidade que se atualizou.

Contrariamente ao que propõem as atuais políticas de diminuição da vida que se alastram pelo mundo, é preciso que se defenda, cada vez com mais ênfase, que a potência da vida não está na redução da multiplicidade e da diferença à uma dada identidade nacional, superior, transcendental, a um comum idealizado, mas no reconhecimento e na valorização dos diferentes modos de existência que coabitam o mundo.

Nesse sentido, temos afirmado que o que há de comum em nossas vidas não é nacional ou o semelhante, mas a diferença e a multiplicidade. Não é o transcendental, mas da ordem do acontecimento, da imanência, do virtual que se atualiza e faz das vidas, devir revolucionário. Para Deleuze e Guattari (2008b, p. 12), o devir: "não se contenta em passar pela semelhança, para o qual a semelhança, ao contrário, seria um obstáculo ou uma parada”. Ampliando essa discussão os autores (2008b, p. 18-19) afirmam que:

Um devir não é uma correspondência de relações. Mas tampouco é ele uma semelhança, uma imitação e, em última instância, uma identificação [...]. O devir não produz outra coisa senão ele próprio. É uma falsa alternativa que nos faz dizer: ou imitamos ou somos. O que é real é o próprio devir, o bloco de devir e não os termos supostamente fixos pelos quais passaria aquele que se torna [...]. Enfim, devir não é uma evolução, ao menos uma evolução por dependência e filiação. O devir nada produz por filiação; toda filiação seria imaginária. O devir é sempre de uma ordem outra que a da filiação. Ele é da ordem da aliança.

Devir pensado, então, como revolução, devir-revolucionário que irrompe com as minorias (DELEUZE; GUATTARI, 2003) criando possíveis para uma educação menor ${ }^{1}$ 
(GALLO, 2002) acontecer, criando fissuras da ordem do instituído, em meio às variações intempestivas, intensidades e fluxos, uma vez que estão nas virtualidades. Ao se referir à educação menor Gallo (2002, p. 173) considera que:

A educação maior é aquela dos planos decenais e das políticas públicas de educação, dos parâmetros e diretrizes, aquela da constituição e da LDB, pensada e produzida pelas cabeças bem-pensantes a serviço do poder [...].

Uma educação menor é um ato de revolta e de resistência. Revolta contra os fluxos instituídos, resistência às políticas impostas; sala de aula como trincheira, como a toca do rato, o buraco do cão [...].

Se a educação maior é produzida na macropolítica, nos gabinetes, expressa nos documentos, a educação menor está no âmbito da micropolítica, na sala de aula, expressa nas ações cotidianas de cada um

A educação menor se constituiria, então, como possibilidade de combater o que está dado na ordem do hegemônico, das práticas de controle e opressão, das padronizações, das formas de conservadorismo e de subalternização que, muitas vezes, se fazem fortalecidas nas políticas de Estado, como acontece no Brasil dos dias atuais. No entanto, como alertam Deleuze e Parnet (2004), não podemos cair no equívoco de pensar o Estado como bloco hegemônico, centralizado e/ou totalitário. Para os autores (2004, p. 174-175):

O erro seria dizer: há um Estado globalizante, senhor dos seus planos e que estende as suas armadilhas; e depois, uma força de resistência que vai adoptar a forma do Estado, arriscando-se a trair-nos, ou que vai cair em lutas locais parciais ou espontâneas, que uma e outra vez serão abafadas e vencidas. O Estado mais centralizado não é, de forma alguma, senhor dos seus planos, pois ele também é experimentador, faz injecções, não conseguindo prever o que quer que seja [...]. É em linhas diferentes de agenciamentos complexos que os poderes realizam as suas experimentações, mas é aí também que surgem experimentações de outro tipo, estragando as previsões, traçando linhas de fuga ativas, procurando a conjugação dessas linhas, precipitando a sua velocidade ou abrandamento, criando fragmento a fragmento o plano de consistência, com uma máquina de guerra que mediria a cada passo os perigos que encontra.

\section{Corpo sem órgãos e máquina de guerra nômade}

A nosso ver, a força dos processos cotidianos de resistência e de criação está no fato de não ser possível pensá-los nos liames das identificações, das semelhanças, das intenções ou do raciocínio lógico, uma vez que são, o tempo todo, provocados pelas dimensões de filiação, diferença e de multiplicidade. Como afirmam Deleuze e Guattari (1996, p. 8):

As multiplicidades são a própria realidade e não supõe nenhuma unidade, não entram em nenhuma totalidade e tampouco pouco remetem a um sujeito. As 
subjetivações, as totalizações, as unificações são, ao contrário, processos que se produzem e aparecem nas multiplicidades. Os princípios característicos das multiplicidades concernem a seus elementos, que são singularidades; as suas relações, que são devires; a seus agenciamentos, que são hecceidades (quer dizer, individuações sem sujeito); a seus espaços-tempos que são espaços e tempos livres; a seu modelo de realização, que é o rizoma (por oposição ao modelo da árvore); a seu plano de composição, que constitui platôs (zonas de intensidade contínua); aos vetores que as atravessam, e que constituem territórios e graus de desterritorialização.

Decorre dessa discussão a necessária destruição da ideia do sujeito autocentrado, identitário e tomado como consciência plena, uma vez que estamos considerando que a "identidade" com a qual uma pessoa se apresenta ou é reconhecida, seria apenas um dos infinitos modos de existência possível.

Nessa direção, seria mais interessante pensar com a "ideia” de corpo sem órgãos (CsO) de Deleuze e Guattari (2008a), onde as intensidades passam e fazem com que não exista mais nem o "eu” nem o "outro”, mas singularidades que não são pessoais, interiores ao sujeito, mas múltiplos processos de singularização que, como práticas de liberdade, se constituem como possibilidades de combate aos modelos de subordinação identitária. De fato, como defendem Deleuze e Guattari (2008a, p. 13):

O CsO é feito de tal maneira que ele só pode ser ocupado, povoado por intensidades. Somente as intensidades passam e circulam. Mas o CsO não é uma cena, um lugar, nem mesmo um suporte onde aconteceria algo. Nada a ver com um fantasma, nada a interpretar. O CsO faz passar intensidades, ele produz e as distribui num spatium ele mesmo intensivo, não extenso. Ele não é o espaço e nem está no espaço, é matéria que ocupará o espaço em tal ou qual grau - grau que corresponde às intensidades produzidas.

Schöpke (2017), ao problematizar os processos de desconstrução das noções de interioridade, de Eu e de consciência, em prol da singularidade, deixa evidente que não se trata de negar uma dada coesão interna. Mesmo considerando que essas noções são signos e instrumentos da moral transcendente e castradora, para a autora (2017, p. 303), “[...] é preciso entender que o processo de dessubjetivações do Eu não significa mergulhar no caos ou na loucura. Dissolver o Eu implica num duplo movimento: o de sua desconstrução e o de sua reconstrução enquanto singularidade”. Assim, podemos inferir que o CsO não tem a ver com loucura ou devassidão, mas refere-se aos processos de criação e de resistência em prol da produção de outros-novos modos de ser.

Ao afirmarem que os $\mathrm{CsO}$ prestam homenagem a Espinosa, para quem não se sabe o que pode um corpo, de que afectos é capaz, e, ainda, que não se tratam nem de uma noção nem de um conceito, mas de um conjunto de práticas, Deleuze e Guattari (2008a) propõem a questão: Como criar para si um CsO?, nos convidando a pensar que o CsO não seria contrário aos órgãos, mas a essa organização que se chama organismo. 
Nesse sentido, o fato de não se saber o que pode um corpo diz respeito, sobretudo, ao fato de que nossa consciência ignora a sua potência, ou seja, diz respeito à impotência de nossa consciência para dar conta de conhecer todas as conexões, todas as intensidades de que um corpo é capaz.

Assim, há que se buscar combater as organicidades, as normas, os padrões, toda transcendência opressora e de diminuição da vida, todos os mecanismos de servidão que se alojam nos organismos-instituições, e que nos dias atuais, sobretudo por conta das políticas governamentais de educação, e em particular as de currículo, se fazem cada vez mais presentes e avassaladoras nas escolas, não se tornando únicas exatamente por conta dos movimentos cotidianos insurgentes de criação e de resistência protagonizados pelos corpos praticantespensantes. Para Schöpke (2017, p. 291):

Para além da tirania que os poderes exercem sobre a vida, e para além mesmo de nossas fictícias sensações de estabilidade, segurança e permanência, o corpo age subterraneamente, exigindo o que lhe é de direito. Seria preciso - se fosse plenamente possível - fazer uma história do corpo que contemplasse, desde que o homem é homem, o seu massacre contínuo e metódico, bem como as derivas para suportar o 'peso da existência'.

O organismo não seria, então, o corpo sem órgãos, mas um estrato atuando sobre ele tentando aprisioná-lo, subjugá-lo como "um fenômeno de acumulação, de coagulação, de sedimentação que lhe impõe formas, funções, ligações, organizações dominantes e hierarquizadas, transcendências organizadas para extrair um trabalho útil” (p. 21).

No entanto, como já dito, o corpo reage, se expande, faz insurgir movimentos de criação e de resistência, em permanente tensão com os modos de opressão. Nesse sentido, com Deleuze e Guattari (2008a), é possível pensar o CsO associado à reorganização das forças intensivas, à revolução por novas formas de existência, à proposição de uma dimensão éticoestético-política para a vida, à luta pela libertação das malhas dos poderes opressores ou, ainda, como defende Schöpke (2017, p. 285), à produção da máquina de guerra nômade:

Em um sentido bem estrito, trata-se da produção de um corpo mais pleno, mais vivo, mais intenso, um corpo de resistência para o desejo e para a própria vida, o que só é possível se desconstruímos o corpo criado para servir docilmente aos poderes do campo social. Só que é aqui que reside o maior de todos os perigos: nem toda desconstrução se converte em criação de um corpo sem órgãos no sentido revolucionário.

Entretanto, como defende a autora (2017), faz-se necessário que a guerra vá além daquela que travamos contra os organismos. De fato, a guerra se constitui pela vida, pela libertação da vida aprisionada no homem e pelo próprio homem. Uma guerra que possa romper com a opressão das forças vitais que torna o corpo refém dos poderes que estão a serviço morte. 
Assim, buscando responder a questão posta por Deleuze e Guattari (2008a), qual seja, “Como criar para si um CsO?”, teríamos como uma possível resposta ser capaz de fazer parte de um devir libertário que expressaria, antes de tudo, a produção de novos modos de ser, de sentir, de existir, de viver, de criar e de resistir. Para Schöpke (2017, p. 295-296):

Em tudo e por tudo, esta é uma guerra que se trava primeiro contra nós mesmos, ou contra aquilo que, em nós, serve a estes poderes. Ou seja, não se produziu uma máquina de guerra se não se entrou em guerrilha consigo mesmo, contra os poderes que estão interiorizados em nós e que, sem perceber, o reproduzimos continuamente. Mas é nesta guerra que o corpo e o pensamento se arriscam e podem sucumbir. É que é preciso implodir o campo de significância dado (mas sem se destruir) e inventar novas maneiras pensar, de ser e de viver. É preciso ir além do niilismo e tomar a vida nas mãos, é preciso ser o esteta de si mesmo. É somente assim que a subjetividade criada para servir aos poderes começa a se diluir em prol da vida e da criação. Afinal, é quando o corpo se liberta que ele pode servir a novas forças; às forças criadoras da vida. Arte e pensamento em uníssono. Novos cantos para novos mundos. Novos usos para as mãos, para a boca, para os ouvidos, para o corpo.

A produção da máquina de guerra nômade estaria relacionada, então, à condição de nomadismo, uma vez que se trata de uma arquitetura inventiva que acontece no âmbito das micropolíticas cotidianas, combatendo as hegemonias da mesmidade, da identidade, da representação e das buscas por consensos. No texto "1227 - Tratado de nomadologia: a máquina de guerra”, Deleuze e Guattari (2007) afirmam que a máquina de guerra é exterior ao aparelho do Estado, sendo de outra espécie, de outra natureza. Tem sua origem diferente do aparelho do Estado. Vinda de outra parte, a máquina de guerra é irredutível ao aparelho do Estado, é exterior à sua soberania e anterior a seu direito.

É que a exterioridade da máquina de guerra em relação ao aparelho do Estado revela-se por toda parte, mas continua sendo difícil pensar. Não basta afirmar que a máquina é exterior ao aparelho, é preciso chegar a pensar a máquina de guerra como sendo ela mesma uma pura forma de exterioridade, ao passo que o aparelho de Estado constitui a forma de interioridade que tomamos habitualmente por modelo, ou segundo a qual temos o hábito de pensar. O que complica tudo é que essa potência extrínseca da máquina de guerra tende, em certas circunstâncias, a confundir-se com uma ou outra das cabeças do aparelho do Estado.

Ao discutirem a produção da máquina de guerra, os autores (2007) inferem que a mesma tem sua origem nos povos de existência nômade que têm por afectos as armas de uma máquina de guerra, sendo efetuada no que nomeiam de agenciamentos bárbaros dos povos nômades guerreiros, cuja vida é intermezzo e a desterritorialização constitui sua relação com a terra, se reterritorializando na própria desterritorialização. Ao considerarem que a máquina de guerra segue as linhas de fuga, os autores (2007, p. 53) inferem que: 
O nômade aparece ali, na terra, sempre que se forma um espaço liso que corrói e tende a crescer em todas as direções. $\mathrm{O}$ nômade habita esses lugares, permanece nesses lugares, e ele próprio os faz crescer, no sentido em que se constata que o nômade cria o deserto tanto quanto é criado por ele. Ele é o vetor de desterritorialização. Acrescenta o deserto ao deserto, a estepe à estepe, por uma série de operações locais cuja orientação e direção não param de variar.

Assim, ao considerarem o nomadismo como uma espécie de máquina de guerra, o que vai importar são os permanentes movimentos de deslocamento e de tensão em meio aos espaçostempos estriados produzidos pelo Estado, oportunizando teorias-práticas de criação e de resistência.

\section{A guisa de conclusão: modos de verolharsentirpensar nossos presentes em sua virtualidade}

Desse modo, mergulhados nas situações do presente - único tempo existente - nos restam dois movimentos possíveis nos tantos espaçostempos que habitamos: resistir a uma agenda criada pelo instituído nas instituições e, cotidianamente, ir criando agendas que brotam de nossas necessidades, de nossas solidariedades, de nossas virtualidades, de nossos possíveis.

Os dois movimentos devem ser entendidos como realizados nos mesmos espaçostempos mas atuados por diferentes motivos e, por isto, criando agendas outras.

Além disso, entendidos como vistosouvidossentidospensados por nossas presenças nas tantas redes educativas que formamos e que nos formam, permanentemente, na busca de nossa vida pessoal e coletiva, entendendo que essas redes se relacionam nos mesmos espaçostempos mas com intensidades diferentes.

$\mathrm{E}$, de certo modo, podemos dizer que só nestas relações é que vivemos, intensa e diversamente, os desafios crescentes que se vem colocando para nós. Nosso movimento de criação não existe porque o queremos, mas porque é uma necessidade da vida em nossos tantos cotidianos. Com ele - e só com ele - podemos agregar os tantos “Es” (e...e...e...) criando um "riacho sem início nem fim, que rói suas duas margens e adquire velocidade no meio” (DELEUZE; GUATTARI, 1996, p. 37).

\section{Nota}

1. Crescentemente, temos buscado substituir este termo - menor - pelo termo miúdo trabalhado por Caputo (2018 a; 2018 b), tal como explicado em texto por Andrade; Caldas; Alves (2019). 


\section{Referências}

ALVES, Nilda; OLIVEIRA, Inês Barbosa de. Uma história da contribuição dos estudos do cotidiano ao campo do currículo. In: LOPES, Alice Casimiro; MACEDO, Elizabeth (Org.). Currículo: debates contemporâneos. São Paulo: Cortez, 2002.

ALVES, Nilda (Org). Criar currículo no cotidiano. São Paulo: Cortez, 2004.

ANDRADE, Nívea; CALDAS, Alessandra Nunes; ALVES, Nilda. Os movimentos necessários às pesquisas com os cotidianos. In OLIVEIRA, Inês Barbosa de; SUSSUKIND, Maria Luiza; PEIXOTO, Leonardo (orgs). Estudos do cotidiano, currículo e formação docente - questões metodológicas, políticas e epistemológicas. Curitiba: CRV, 2019: s p (no prelo)

BARROS, Gustavo de Almeida; MUNARI, Silvio Ricardo; ABRAMOWICZ, Anete. Educação, cultura e subjetividade: Deleuze e a diferença. Revista Eletrônica de Educação, v. 11, n. 1, p.108-124, jan./maio, 2017.

CAPUTO, Stela Guedes. APP-Ethnoresearching: múltiplos e simultâneos usos de aplicativos no fazer etnográfico. In Edméa Santos; Stela Guedes Caputo (orgs). Diário de pesquisa na cibercultura. Rio de Janeiro: OMODÉ, 2018a.

Reparar miúdo, narrar Kéreké - notas sobre nossa fotoetnopoética com crianças de terreiros. Revista Teias, v.19, Abr./Jun. 2018b, (53): 36 - 63.

DELEUZE, Gilles. Lógica do sentido. São Paulo: Perspectiva, 2007.

DELEUZE, Gilles; GUATTARI, Félix. Mil Platôs: Capitalismo e Esquizofrenia. V.3. Rio de Janeiro: Ed. 34, 2008 .

DELEUZE, Gilles; GUATTARI, Félix. Mil Platôs: Capitalismo e Esquizofrenia. V.4. Rio de Janeiro: Ed. 34, $2008 b$.

DELEUZE, Gilles; GUATTARI, Félix. Kafka: por uma literatura menor. Lisboa: Assírio Alvim, 2003.

DELEUZE, Gilles; GUATTARI, Félix. O que é a filosofia? Rio de Janeiro: Ed. 34, 1992.

DELEUZE, Gilles; GUATTARI, Félix. Mil Platôs: Capitalismo e Esquizofrenia. V.1. Rio de Janeiro: Ed. 34, 1996.

DELEUZE, Gilles; PARNET, Claire. Diálogos. Lisboa: Relógio D’Água, 2004.

GALLO, Silvio. Em torno de uma educação menor. Revista Educação e Realidade, Porto Alegre, v. 27, n. 2, jul./dez. 2002.

OLIVEIRA, Inês Barbosa de. Currículos e pesquisas com os cotidianos: o caráter emancipatório dos currículos 'pensadospraticados' pelos 'praticantespensantes' dos cotidianos das escolas. In: FERRAÇO, Carlos Eduardo; CARVALHO, Janete Magalhães (Org.) Currículos, pesquisas, conhecimentos e produção de subjetividades. Petrópolis: DP et Alii, 2012.

OLIVEIRA, Inês Barbosa de; ALVES, Nilda. Contar o passado, analisar o presente e sonhar o futuro. In: OLIVEIRA, Inês Barbosa de; ALVES, Nilda. Pesquisa no/do cotidiano das escolas: sobre redes de saberes. Rio de Janeiro: DP\&A, 2001.

SANTOS, Boaventura de Sousa. Pela mão de Alice: o social e o político na pós-modernidade. São Paulo: Cortez, 1995.

SCHÖPKE, Regina. Corpo sem órgãos e a produção da singularidade: a construção da máquina de guerra nômade. Revista de Filosofia Aurora. v. 29, n. 46, p.285-305, jan./abr. 2017. 


\section{Correspondência:}

Nilda Guimarães Alves: Professora titular da UERJ e da UFF (aposentada em ambas). Pesquisadora visitante emérita/Faperj, atuando na UERJ, no Programa de Pós-graduação em Educação (campus Maracanã) e no PPGE-Processos Formativos e Desigualdades Sociais (campus S. Gonçalo). Pesquisadora 1 A/CNPq.

E-mail: nildag.alves@gmail.com

Carlos Eduardo Ferraço: Doutor em Educação pela USP (2000) na área de Didática, com Pós-Doutorado em Educação pela UERJ (2008 e 2015), atuando como Professor Titular no Programa de Pós-Graduação em Educação da Universidade Federal do Espírito Santo. É bolsista de produtividade de pesquisa do Cnpq e líder do GRPEs/CNPq Currículos, cotidianos, culturas e redes de conhecimentos, desenvolvendo investigações no campo do Currículo em suas relações com os cotidianos das escolas.

E-mail: ferraco@uol.com.br

Marco Antonio Oliva Gomes: Doutor em Educação pela Ufes (2012) na área de Currículo, Cultura e Formação de Educadores, atuando como Professor Adjunto no Departamento de Teorias do Ensino e Práticas Educacionais do Centro de Educação da Universidade Federal do Espírito Santo. É vice-líder do GRPEs/CNPq Currículos, cotidianos, culturas e redes de conhecimentos, desenvolvendo investigações no campo do Currículo em suas relações com a formação de educadores e os processos inclusivos.

E-mail: paramarcoantonio@uol.com.br

Texto publicado em Currículo sem Fronteiras com autorização dos autores 